\title{
Frequency Stabilisation Using VSC-HVDC
}

Link to publication record in Manchester Research Explorer

\section{Citation for published version (APA):}

Shen, L., Barnes, M., Preece, R., \& Milanovic, J. (2016). Frequency Stabilisation Using VSC-HVDC. In 2016 IEEE PES GM Proceedings IEEE.

\section{Published in:}

2016 IEEE PES GM Proceedings

\section{Citing this paper}

Please note that where the full-text provided on Manchester Research Explorer is the Author Accepted Manuscript or Proof version this may differ from the final Published version. If citing, it is advised that you check and use the publisher's definitive version.

\section{General rights}

Copyright and moral rights for the publications made accessible in the Research Explorer are retained by the authors and/or other copyright owners and it is a condition of accessing publications that users recognise and abide by the legal requirements associated with these rights.

\section{Takedown policy}

If you believe that this document breaches copyright please refer to the University of Manchester's Takedown Procedures [http://man.ac.uk/04Y6Bo] or contact uml.scholarlycommunications@manchester.ac.uk providing relevant details, so we can investigate your claim.

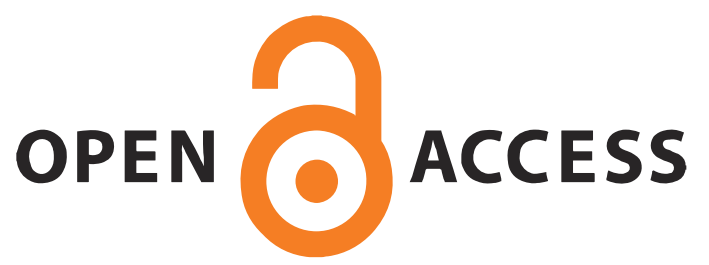




\section{Frequency Stabilisation Using VSC-HVDC}

\author{
Li Shen \\ State Grid Sichuan Economic Research Institute, \\ Chengdu, 610041, China
}

\begin{abstract}
Frequency control of AC systems using Voltage Source Converter (VSC) HVDC links is of growing importance as interconnectors and links to offshore generation replace conventional synchronous generators in many countries. This paper investigates the use of local system feedback and advanced droop control to achieve frequency stabilization for a two-area test system.
\end{abstract}

Index Terms - HVDC transmission, Inverters, Power control, Power systems stability, Wind energy integration .

\section{INTRODUCTION}

A major disturbance, such as the loss of a major tie-line or a sudden change in the load demand, will cause a generation/demand imbalance in AC power systems. Over short time frames (a few or tens of seconds), imbalances between generation and demand have traditionally been managed using frequency response services such as turbine governing systems. As VSC-HVDC interconnectors and renewable energy interfaced through VSC-HVDC replace local synchronous generation, there is a growing need to utilize VSC HVDC control to help support the frequency of the local system following power imbalances. VSC-HVDC can respond more quickly to power unbalance than conventional synchronous generators because of the fastacting control possible with power electronics. Using VSCHVDC controllers to support AC transmission system following frequency disturbances has been the subject of much recent research [1-4]. In spite of this there is no standard frequency support methodology at present. This paper explores a droop-based control of VSC-HVDC to provide frequency support to AC transmission system.

\section{PROBLEM DESCRIPTION}

\section{A. General Case}

A generic example of a VSC HVDC supplied area subjected to major system disturbance can be used to explain the fundamentals of frequency disturbance problem. The local system is originally supplied by a generator and a VSC HVDC link through a main transmission line. The turbine governor system of the local generator can adjust its mechanical power input to match the new electric power output after the fault. Additional power control of the VSC HVDC link can be used to mitigate the power mismatch more

\author{
Mike Barnes, R Preece, JV Milanović \\ University of Manchester \\ School of Electrical and Electronic Engineering \\ Manchester, M13 9PL, UK
}

quickly. Since many VSC HVDC links are normally operated at their maximum available power ${ }^{1}$, the available power reserve for frequency regulation is limited, hence the VSCHVDC control may be most useful in situations where a power reversal is needed to reach a new power equilibrium point.
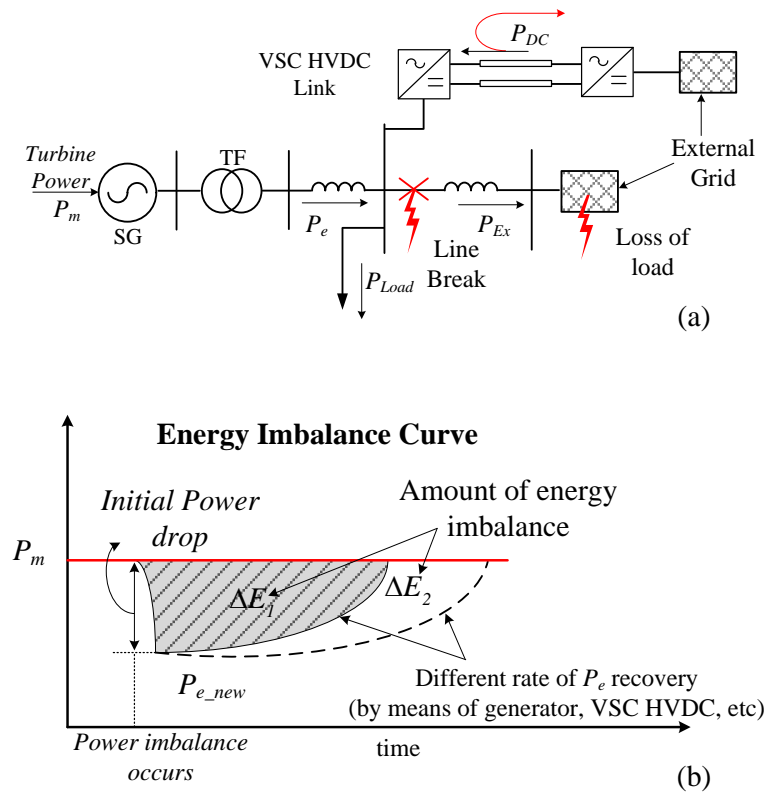

Figure 1 (a) Diagram for specific case study and (b) Representation of power imbalance in the system.

As shown in Figure 1 (a), the original system power balance is as given in (1).

$$
\Delta P=\Delta(f, v, p h i) \cdot k_{d r o o p}
$$

Figure 1 (b) depicts the case of power imbalance when the middle line is disconnected following a short circuit, i.e., $P_{E x}$ $=0$. The amount of energy mismatch in the local system $\Delta E$ depends on the speed of re-establishing the power balance in the system. The faster the power compensation is provided, the smaller the energy mismatch and the system is more likely to be stable after the fault.

\footnotetext{
${ }^{1}$ VSC-HVDC converters have limited overload capability. For windfarm connected systems, the HVDC link would carry the maximum power available for the windfarm. For interconnectors, the situation depends on contracted supply arrangements.
} 


\section{B. Simulation Case}

Possible system control strategies are tested on a modified two-area test system with a VSC HVDC link, as shown in Figure 2 (there is only one tie-line between bus 7 and 8 ). The purpose of this example is to investigate the dynamic responses of the power system immediately following a major system fault. Consider the worst case scenario where the load in this local area is a static constant MVA load and there is neither turbine governor nor VSC HVDC power support. The VSC HVDC link is operated with VSC1 regulating the DC side voltage and VSC2 in constant power control. The external grid is assumed to be a strong AC system represented by an infinite bus that has enough capacity to take full power reversal in the DC link. Both generators are equipped with AVR and PSS.

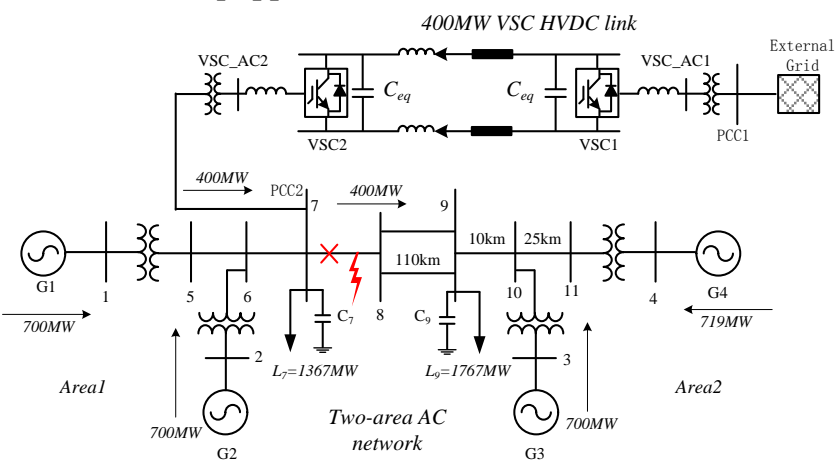

Figure 2. Test system with VSC HVDC link.
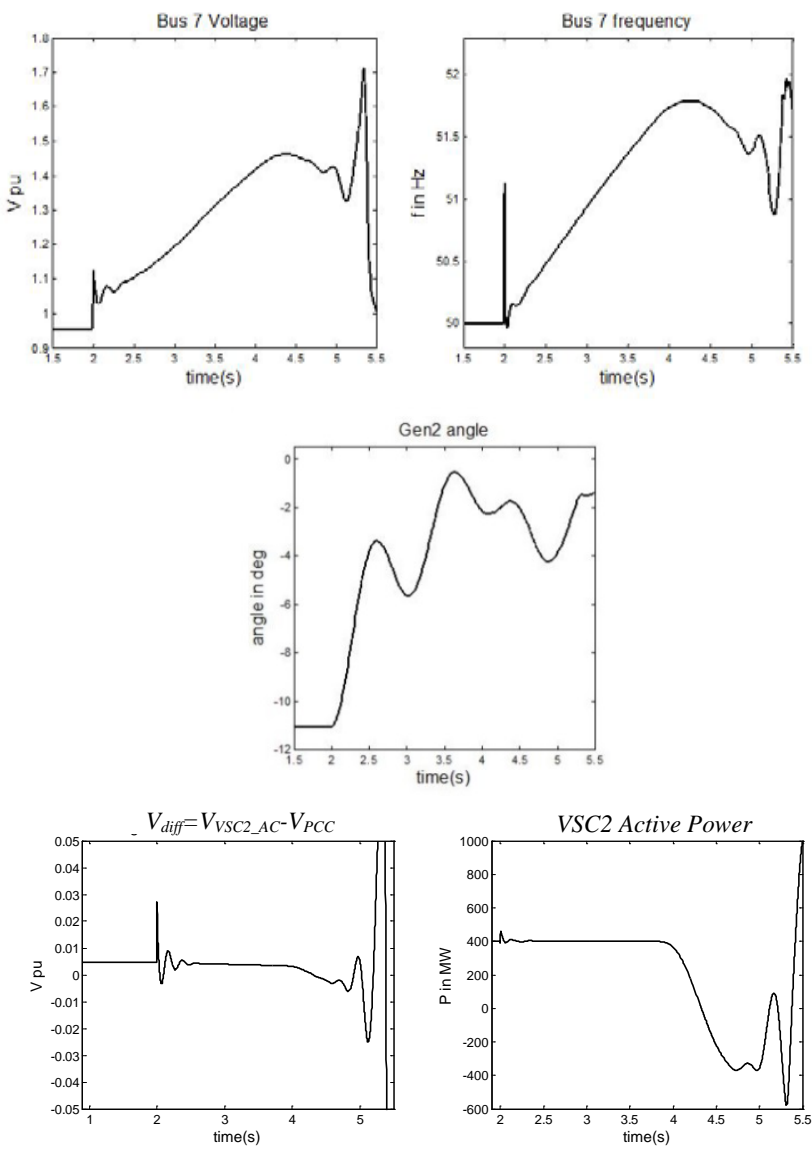

Figure 3 Test system responses for tie-line disconnection event.
A tie-line (line 7-8) is disconnected at $2 \mathrm{~s}$. The initial power exported from Area 1 to Area 2 (400 MW and 100 MVAr) drops to zero due to the line break. The system responses are presented in Figure 3. It can be seen that the system voltage and frequency start to increase until instability occurs after $5 \mathrm{~s}$ and the phase angle at the generator bus 2 with reference to the slack bus is also affected. The generator turbine power does not change as there is no governor at generator 2 . The generator terminal voltage increases due to the fact that the voltage drop on the generator reactance decreases while the generated emf is the same. The voltage continues to rise as there is more reactive power injected into the local system than exported, until its brought down to set value by the AVR.

Meanwhile, the VSC HVDC link is also affected by the fault. The PCC bus 7 voltage increases beyond the maximum VSC2 AC side voltage that can be synthesised from the DC link after the fault. (The voltage difference between bus VSC_AC2 and bus PCC2 is shown in Figure 3 as $\mathrm{V}_{\text {diff }}$ ). It can be seen that the VSC_AC2 bus voltage actually becomes lower than the PCC2 bus voltage after 4.5s. Under such circumstances the power from the DC side does not follow the normal rules for linear output AC voltage modulation and transfer into the local AC system, causing the DC link power to be reduced and reversed (Figure 3 lower right). DC system instability is observed after $5 \mathrm{~s}$.
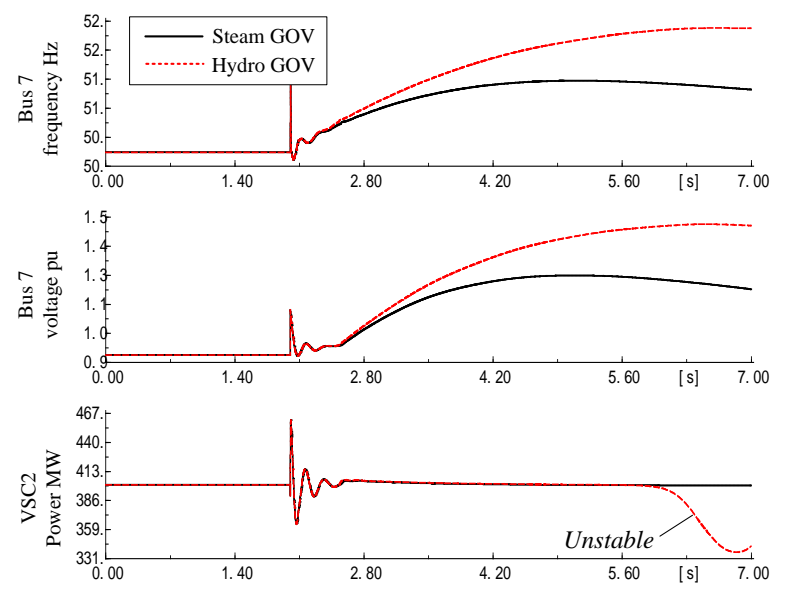

Figure 4. System responses with steam and hydro type governors.

To address these problems, the turbine governors can be used to a certain extent to maintain system stability. However hydraulic turbine governors are normally designed to have relatively large transient droops and longer resetting times than steam turbine governors, and therefore they have slower responses [5], Figure 4, which may hamper their effectiveness. Steam type turbine governing systems provide a quicker turbine power adjustment to restore power balance in the system, and thus the system is stabilized following the event. The system with slower hydraulic governors cannot quickly reach a new equilibrium point, which results in instability in the VSC HVDC link. The simulation results obtained from the test system suggest that instability could occur on both AC and DC sides of the system when power imbalance occurs under situations of: (1) no control actions 
taken or (2) the control actions taken are not fast enough. In the following sections, the capability of the VSC HVDC link to provide power support to the grid is examined. Different types of control schemes in the grid connected VSC are proposed to meet the system stability requirements.

\section{VSC-HVDC CONTROL TO RESTORE POWER BALANCE}

Droop control settings can be used in the grid connected converters to enable the VSC HVDC link to contribute in maintaining system power balance. Some forms of droop control structure have been proposed in $[6,7]$ for main grid frequency support. In this case, any of the three signals (voltage, frequency or local angle) can be used and their block diagram representation is shown in Figure 5. With this configuration, the active power reference set point is modified by the input signal through a droop gain setting (1) but voltage and phase angle are now provided by phasor measurement units (PMU) devices.

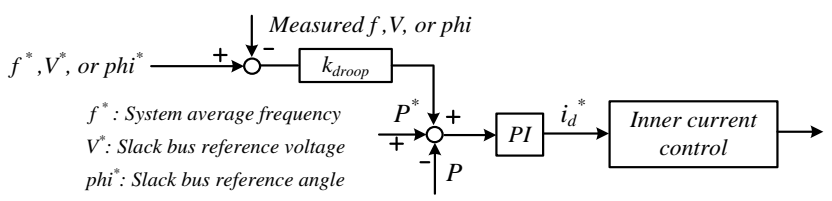

Figure 5. Droop type control to enable VSC HVDC for system power support.

An auxiliary signal is sent to the grid connected converter VSC2 modifying its power reference set point when subjected to the tie-line disconnection event. Different droop gain values are applied to show their effect on the system stability performance after the fault.

\section{A. Droop Control with Frequency and Voltage as Inputs}

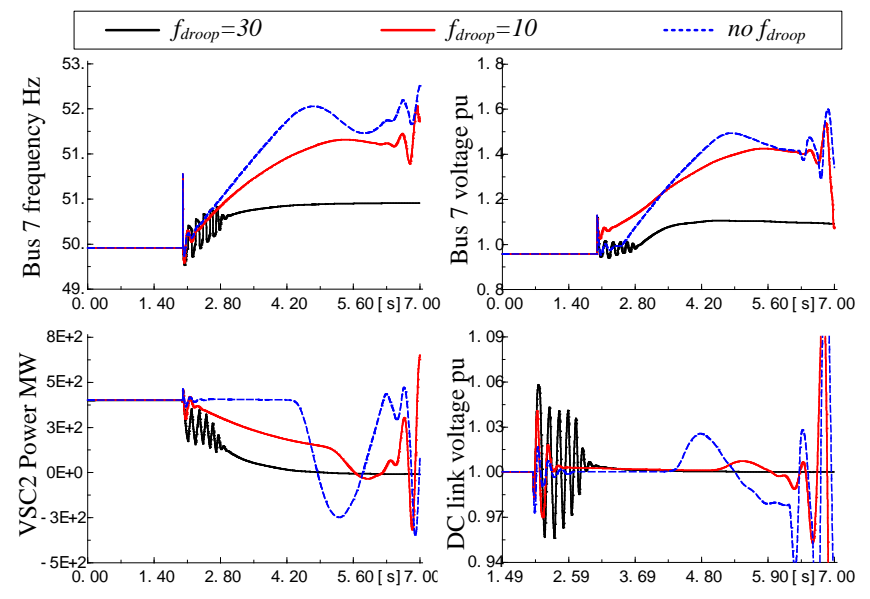

Figure 6. System responses with frequency droop control.

The system responses are presented in Figure 6 and Figure 7 when the measured frequency and voltage are used as the input signals. The case without the droop control is also presented in Figure 6 which goes unstable after 5s. With the frequency droop control applied, the VSC HVDC starts to reduce its active power injection to reach a new equilibrium point. For a small droop gain settings $\left(f_{\text {droop }}=10\right)$, the power reduction in the VSC HVDC is not fast enough and results in system instability after $6.5 \mathrm{~s}$. When the droop gain is increased $\left(f_{\text {droop }}=30\right)$, the system is stabilized after the fault event. Therefore, in this case, the speed of power reduction in the DC link varies with the droop gain value - the larger the droop gain value, the faster the power reduction / reversal.
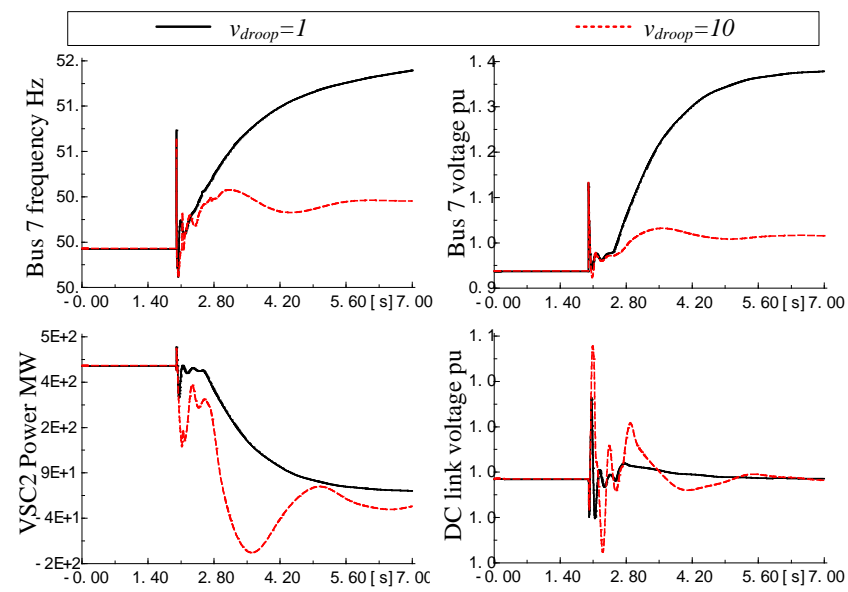

Figure 7. System responses with PCC voltage droop control.

When the measured voltage is used as the input signal, both voltage droop gains $\left(v_{\text {droop }}=1\right.$ and 10) stabilize the system after the fault event (Figure 7). Again, a higher droop gain results in faster power change in the VSC HVDC and reduced voltage and frequency deviations in the system.

\section{B. Droop Control with Measured Phase Angle as Input}

With rapid advancements in wide-area measurement system (WAMS) technology, remote signals in the power systems are made to be available in local controls by utilizing synchronized PMUs at a rate up to $60 \mathrm{~Hz}[8,9]$, and using the measured phase angle as an auxiliary signal for modifying VSC power reference settings. However, typical time delays can be up to 1s [9] depending on the distance, transmission channel and other technical factors. This is close to the time constants for the controls employed in the VSC HVDC link, and possibly deteriorates the controllers' dynamic performance. To incorporate the delays in the model, a delay function was added expressed as in (2).

$$
G_{\text {delay }}(s)=e^{-s T_{\text {delay }}}
$$

In this case, a PMU is placed at generator bus 2 and measures its phase angle with respect to the slack bus angle. This value is used as an input signal to the droop control employed in VSC2. The simulation of the tie-line disconnection shows that the phase-angle droop-control is also able to modify the VSC output power and stabilize the system after the fault without considering the time delay in signal transmission. Variations in the droop gain value have similar effects as the cases with frequency and voltage type droop controls. However, when time delay in the signal transmission is considered (with the model shown in Figure 8), the performance of the controller appeared to be poor and was even worse with increasing amount of delay, becoming unstable with a time delay larger than 700ms. 

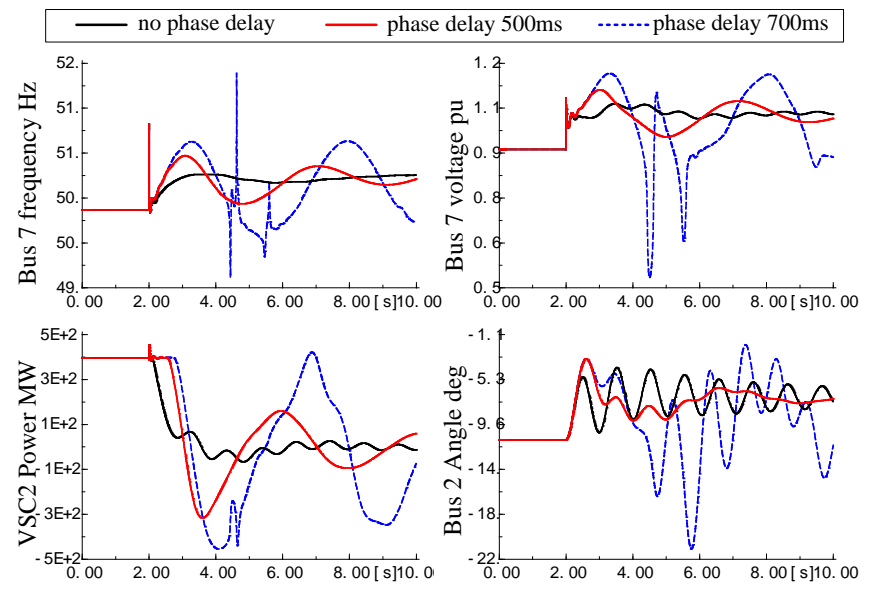

Figure 8. System responses with PMU phase angle droop control considering time delay.

\section{General Discussion on Droop Controls}

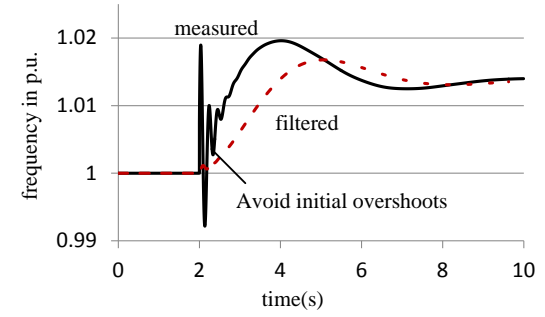

Figure 9. Effect of low pass filter for the measured frequency signal.

It can be seen from the previous investigations that with a larger droop gain setting, the speed of power response increases. Meanwhile, the magnitude of the oscillations in the DC voltage also increases significantly. However, this is mainly due to the initial overshoots in the measured signals when the fault occurs. Therefore, a low pass filter (LPF) may be required for the measured signal to remove the initial overshoots as well as any higher frequency oscillations, Figure 9.

For a relatively large droop gain value, the reference power set point of the VSC HVDC varies with the measured signals, even in normal operating conditions where very small fluctuations exist. This can result in undesirable power oscillations in the VSC HVDC system under normal conditions. The droop gain also needs to be properly tuned for different system conditions depending on the plant model. For instance, the magnitude of frequency deviation can vary with system inertia and type and severity of fault, which will then affect the amount of power support provided by VSC HVDC. Although large droop gain values increase the response speed of the VSC HVDC, they can also deteriorate the DC system dynamic performance and lead to instability.

\section{MODIFIED CONTROL SCHEME}

In practice, voltage based droop controls are normally used as an auxiliary signal to modify reactive power references instead of active power references. Also, the phase angles in the system are always varying and it is difficult to keep track of the phase angle difference between a particular bus where PMUs are installed and the slack bus. Therefore, a modified control scheme proposed in this section is based on the type of droop control using frequency measurements as the input to address the problems raised before.

The UK Transmission System Operator, National Grid has real time system frequency historic data which suggests a normal frequency fluctuation between $\pm 0.1 \mathrm{~Hz}$. With a large frequency droop gain value, very small fluctuations in the measured frequency signal may cause undesirable power variations in VSC HVDC. Therefore, the power reference set point should not be disturbed by small frequency variations. The modified droop characteristic for a VSC HVDC link is proposed, as illustrated in Figure 10.

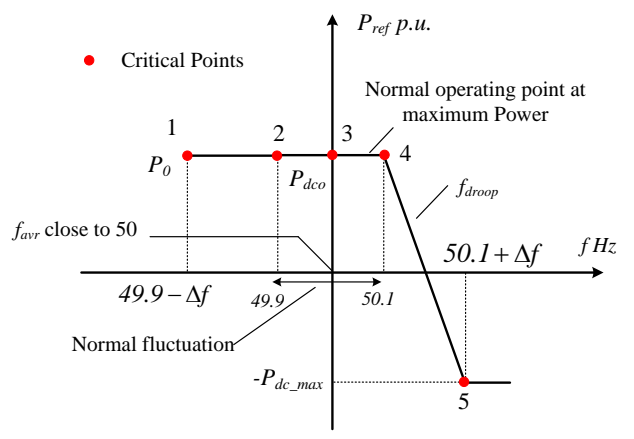

Figure 10 Modified frequency droop characteristic.

A small dead-band characteristic of $\pm 0.1 \mathrm{~Hz}$ is included for the droop type control to avoid active power oscillations due to small frequency fluctuations (similar as one applied in conventional governors). A single-time constant Low Pass Filter (LPF) is added for the measured signals to remove overshoots and higher frequency oscillations, see Figure 11. High pass filters may also be added to remove steady-state frequency offset in practical cases.

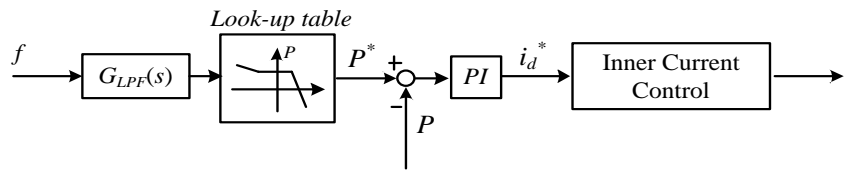

Figure 11 Block diagram of the modified frequency droop control.

An initial selection of the frequency droop gain can be made based on the initial rate of change of frequency (RoCoF) $[10]^{2}$. The rate of change of power in the VSC HVDC is then jointly determined by the RoCoF and the droop gain value. In this two-area system case a 'typical' power imbalance is around $400 \mathrm{MW}$ and synchronous generators are used with inertia constants $\mathrm{H}_{1}=\mathrm{H}_{2}=6.5 \mathrm{~s}$. The bandwidth of the VSC HVDC power loop can be in a range between a few $\mathrm{Hz}$ to tens of $\mathrm{Hz}$. Therefore, a reaction time for the VSC HVDC of $0.5 \mathrm{~s}$ to reverse its full power is reasonable. This gives an estimated frequency droop design as shown in Figure 10, as described by (3) and (4).

$$
\Delta f=k_{\text {RoCoF }} \times \text { reaction time }(t)=\frac{\Delta P \cdot t}{2 H_{e q}^{\prime}}
$$

\footnotetext{
2 Eventually other controls come into play, but the initial frequency deviation is set by inertia and possibly fast power electronic units such as VSC HVDC
} 


$$
H_{e q}^{\prime}=\frac{\sum_{i=1}^{n}\left(H_{i} S_{B i}\right)}{\sum_{i=1}^{n}\left(S_{B i}\right)}
$$
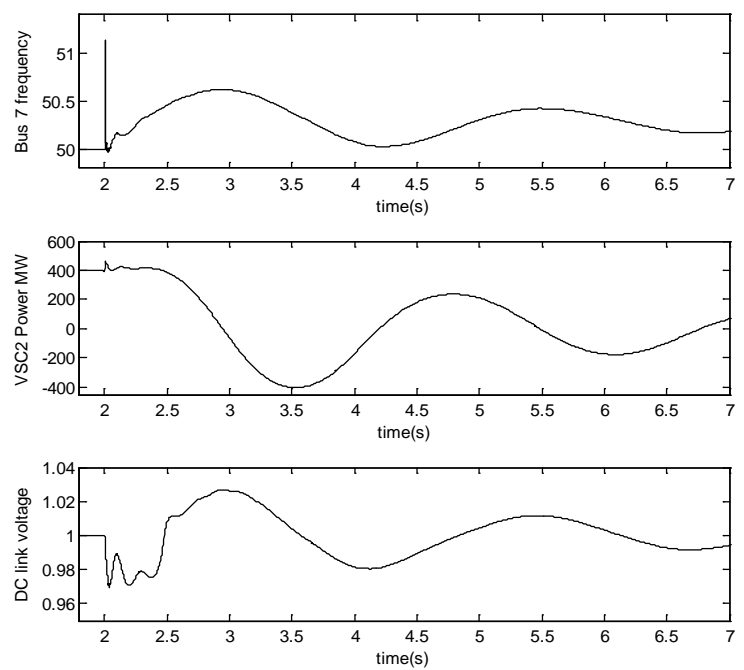

Figure 12. System responses with modified frequency droop control.

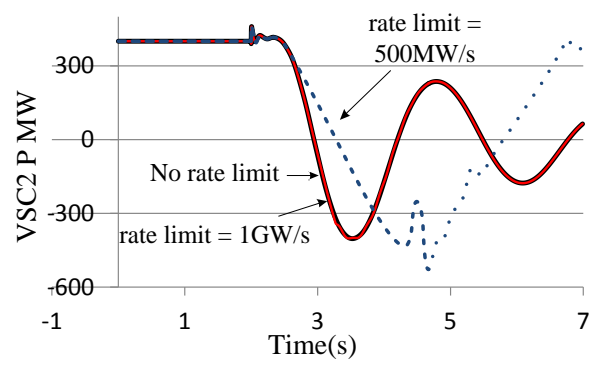

Figure 13. Comparison of VSC2 power responses with the effect of rate limiter.

The VSC HVDC link is operated at its maximum power rating of 400MVA. Figure 12 presents the system responses with the proposed control in VSC2 for the tie-line disconnection. It can be seen that the system is stabilized after the fault. The magnitude of oscillations in the DC side voltage is reduced in comparison with the responses shown previously in Figure 6. The VSC HVDC link provides full power reversal with the designed droop setting. A rate limiter [11] can be added to the dq current reference value if this needs to be limited. In this case, an emergency rate limiter of $1 \mathrm{GW} / \mathrm{s}$ and a reduced rate limiter of 500MW/s are assumed to be applied in the VSC HVDC link. The power response of VSC2 with a frequency droop gain of 30 is affected by the rate limiter as presented in Figure 13.

It is seen that the output power from the DC link is not affected when the emergency rate limit of $1 \mathrm{GW} / \mathrm{s}$ is used. When a slow rate limiter $(500 \mathrm{MW} / \mathrm{s})$ is applied, the rate of change of power exceeds these limitations. As a result, the power can only change at the limited rate. Therefore, in the case that a rate limiter is required (from the AC system point of view) in the VSC HVDC link, its effect needs to be taken into consideration when designing a droop based adaptive power controller. The detailed parameterization of such systems would in any case require local system studies to include factors such as inertia and frequency protection settings of loads and generators [12].

\section{CONCLUSIONS}

The effects of droop gain modification based on local voltage, angle or frequency feedback applied to VSC-HVDC converters have been illustrated in the paper. It has been found that, as with typical feedback systems, a higher droop gain results in faster power change in the VSC HVDC and less voltage and frequency deviations in the system. The droop gains, however, must be properly selected for the system under consideration as they, if too large, could deteriorate the DC system dynamic performance and ultimately lead to instability. Excessive time delays (e.g., greater than 700ms) in the feedback loop could also lead to system instability. Lastly a modified control scheme for frequency based droop control involving small dead-bands and filters is proposed to ameliorate the effect of power oscillations under normal operation. It was shown that the output power change rate limiters can significantly affect the results.

\section{ACKNOWLEDGEMENTS}

The authors gratefully acknowledged National Grid for funding this work under project MAN/22119.

\section{REFERENCES}

[1] Hongzhi Liu and Zhe Chen, "Contribution of VSC-HVDC to Frequency Regulation of Power Systems With Offshore Wind Generation”, IEEE Trans. Power Delivery, vol. 30, pp. 918-926, 2015

[2] Minyuan Guan, Wulue Pan, Jing Zhang, Quanrui Hao, Jingzhou Cheng and Xiang Zheng, "Synchronous Generator Emulation Control Strategy for Voltage Source Converter (VSC) Stations”, IEEE Trans. Power Systems, vol. 30, pp. 3093-3101, Nov. 2015

[3] Adrià Junyent-Ferré, Yousef Pipelzadeh and Tim C. Green, "Blending HVDC-Link Energy Storage and Offshore Wind Turbine Inertia for Fast Frequency Response”, IEEE Trans. Sustainable Energy, vol. 6, pp. 1059-1066, July 2015

[4] Robin Preece, Jovica V. Milanović, Abddulaziz M. Almutairi and Ognjen Marjanovic, "Damping of Inter-Area Oscillations in Mixed AC/DC Networks Using WAMS Based Supplementary Controller", IEEE Trans. Power Systems, vol. 28, pp. 1160-1169, May 2013

[5] P. Kundur, Power System Stability and Control. McGraw-Hill, 1994.

[6] T. M. Haileselassie, R. E. Torres-Olguin, T. K. Vrana, K. Uhlen, and T. Undeland, "Main grid frequency support strategy for VSC-HVDC connected windfarms with variable speed wind turbines," in IEEE PowerTech, Trondheim, pp. 1-6, 2011.

[7] N. R. Chaudhuri, R. Majumder, and B. Chaudhuri, "System Frequency Support Through Multi-Terminal DC (MTDC) Grids," IEEE Transactions on Power Systems, vol. 28, pp. 347-356, 2013.

[8] B. Chaudhuri, R. Majumder, and B. Pal, "Wide area measurement based stabilizing control of power system considering signal transmission delay," in IEEE Power Engineering Society General Meeting, p. 1447 Vol. 2, 2005.

[9] D. Dotta, A. S. e Silva, and I. C. Decker, "Wide-Area MeasurementsBased Two-Level Control Design Considering Signal Transmission Delay," IEEE Transactions on Power Systems, vol. 24, pp. 208-216, 2009.

[10] A. A. Girgis and W. L. Peterson, "Adaptive estimation of power system frequency deviation and its rate of change for calculating sudden power system overloads," IEEE Transactions on Power Delivery, vol. 5, pp. 585-594, 1990.

[11] J. Peralta, H. Saad, S. Dennetiere, J. Mahseredjian, and S. Nguefeu, "Detailed and Averaged Models for a 401-Level MMC HVDC System," IEEE Transactions on Power Delivery, vol. 27, pp. 15011508, 2012.

[12] B. Hoseinzadeh, F.F. Silva, C.L. Bak, "Decentralised Coordination of Load Shedding andPlant Protection Considering High Share of RES", IEEE Transactions on Power Systems, 2015, available online 